\title{
c-Fos expression in the hypothalamic paraventricular nucleus after a single treatment with a typical haloperidol and nine atypical antipsychotics: a pilot study
}

\author{
Alexander Kiss \\ Institute of Experimental Endocrinology, Biomedical Research Center, Slovak Academy of Sciences, Bratislava, Slovakia \\ E-mail:alexander.kiss@savba.sk
}

Objective. The aim of the present study was to find out whether acute effect of different doses of selected antipsychotics including aripiprazole (ARI), amisulpride (AMI), asenapine (ASE), haloperidol (HAL), clozapine (CLO), risperidone (RIS), quetiapine (QUE), olanzapine (OLA), ziprasidone (ZIP), and paliperidone (PAL) may have a stimulatory impact on the c-Fos expression in the hypothalamic paraventricular nucleus (PVN) neurons.

Methods. Adult male Wistar rats weighing 280-300 g were used. They were injected intraperitoneally with vehicle or antipsychotics in the following doses ( $\mathrm{mg} / \mathrm{kg}$ of b.w.): ARI $(1,10,30)$, AMI $(10,30), \operatorname{ASE}(0.3), \operatorname{HAL}(1.0,2.0), \operatorname{CLO}(10,20)$, RIS $(0.5,2.0)$, QUE (10, 20), OLA (5, 10), ZIP (10, 30 ), and PAL (1.0). Ninety min later, the animals were anesthetized with Zoletil and Xylariem and sacrificed by a transcardial perfusion with $60 \mathrm{ml}$ of saline containing $450 \mu \mathrm{l}$ of heparin (5000 IU/l) followed by $250 \mathrm{ml}$ of fixative containing $4 \%$ paraformaldehyde in $0.1 \mathrm{M}$ phosphate buffer (PB, $\mathrm{pH}$ 7.4). The brains were postfixed in a fresh fixative overnight, washed two times in $0.1 \mathrm{M} \mathrm{PB}$, infiltrated with $30 \%$ sucrose for 2 days at $4^{\circ} \mathrm{C}$, frozen at $-80^{\circ} \mathrm{C}$ for $120 \mathrm{~min}$, and cut into $30 \mu \mathrm{m}$ thick serial coronal sections at $-16^{\circ} \mathrm{C}$. c-Fos profiles were visualized by nickel intensified DAB immunohistochemistry and examined under Axio-Imager A1 (Zeiss) light microscope.

Results. From ten sorts of antipsychotics tested, only six (ARI-10, CLO-10 and CLO-20, HAL-2, AMI-30, OLA-10, RIS-2 mg/kg b.w.) induced distinct c-Fos expression in the PVN. The antipsychotics predominantly targeted the medial parvocellular subdivision of the PVN.

Conclusions. The present pilot study revealed c-Fos expression increase predominantly in the PVN medial parvocellular subdivision neurons by action of only several sorts of antipsychotics tested indicating that this structure of the brain does not represent a common extra-striatal target area for all antipsychotics.

Key words: aripiprazole, amisulpride, asenapine, haloperidol, clozapine, risperidone, quetiapine, olanzapine, ziprasidone, paliperidone, c-Fos immunohistochemistry, PVN, rat

The PVN has been shown to be one of the most important control centers in the brain (Swanson and Sawchenko 1980, 1983; Herman et al. 2003, 2008). It has been described as a complex nucleus, comprising of neurons, which potentially play a significant neuroendocrine role in controlling the hypothalamic-pituitary-adrenal (HPA) axis [corticotropin-releasing hormone (CRH) neurons projecting to the median eminence] (Sawchenko and Swanson 1985; Silverman et al. 1989; Lennard et 
al. 1993), the thyroid axis [thyrotropin-releasing hormone (TRH) neurons projecting to the median eminence] (Segerson et al. 1987; Blake et al. 1992; Merchenthaler and Liposits 1994; Alexander et al. 2005), the reproductive axis [dopamine and oxytocin (OXY) neurons projecting to the median eminence or posterior pituitary] (Hou-Yu et al. 1986), the growth and development (somatostatin neurons projecting to the median eminence) (Ishikawa et al. 1987; Merchenthaler et al. 1989), and the regulation of body fluid balance [vasopressin (AVP) and OXY neurosecretory cells projecting to the posterior pituitary] (Hill 2012). The PVN is also the principal source of descending autonomic pathways sending direct projections to the parasympathetic preganglionic neurons (the salivatory nuclei, the dorsal motor nucleus of the vagus, the nucleus ambiguus) and sympathetic preganglionic neurons in the intermediolateral cell column of the spinal cord (Ranson et al. 1998; Hallbeck 2000; Hill 2012). These PVN descending fibers are peptidergic, using OXY and AVP as major transmitters, but the fibers are positive also for CRH, enkephalin, dynorphins, TRH, somatostatin, vasoactive intestinal polypeptide, and angiotensin II (Sawchenko and Swanson 1985; Ceccatelli et al. 1991; Hallbeck et al. 2001). Anatomical studies have demonstrated the basic cell architecture of the PVN in association with their recognized functional clarification, which allows to perform approximate functional classification also in experimentally activated neurons without phenotype identification of the c-Fos-bearing cells (Swanson et al. 1986). Based on the cytoarchitectonic analysis, the PVN has been divided into eight distinct subdivisions, three magnocellular and five parvocellular (Swanson and Kuypers 1980) distributed within three rostral-caudal (anterior, middle, posterior) levels, which generally indicate also the distribution and spatial organization of CRH, OXY, and AVP subset of neuros (Hou-Yu et al. 1986).

Although antipsychotic studies regarding the c-Fos activation have been oriented to many different extra-striatal brain structures, little attention has been given to the PVN. Differences in c-Fos expression after acute treatment with clozapine, chlorpromazine, and fluphenazine have been evaluated in appetite-related centers of the rat brain including the arcuate, paraventricular hypothalamic, and paraventricular thalamic nuclei and the nucleus incertus (Rajkumar et al. 2013). Increased c-Fos immunoreactivity after acute olanzapine treatment, which dose-dependently disrupted various components of the maternal behavior, has been demon- strated, among others, in the central amygdala and the ventral tegmental area (Zhao and Li 2012). Effect of aripiprazole and haloperidol has been investigated on c-Fos-like immunoreactivity presence in the prefrontal cortex and amygdala (Park et al. 2011a). In situ hybridization of c-fos mRNA expression has been reported in rat prefrontal cortex, striatum, nucleus accumbens, and lateral septum after treatment with typical (haloperidol, fluphenazine) and atypical (sulpiride, clozapine, OPC-14597) antipsychotics indicating that from the striatal structures only the nucleus accumbens shell portion responded by increased c-fos mRNA expression (Semba et al. 1996). c-Fos immunohistochemistry has also been used to identify brain regions associated with inverse incentive learning after haloperidol sensitization on the bar test in rats (Pezarro Schimmel et al. 2015). Divergent effect of mosapramine and other antipsychotic drugs including clozapine, haloperidol, and risperidone on the c-Fos protein expression has been demonstrated in the medial prefrontal cortex, nucleus accumbens and dorsolateral striatum of the rat (Fujimura et al. 2000). Distinctive patterns of Fos expression has been observed after acute administration of typical antipsychotic chlorpromazine and atypical antipsychotics (clozapine, thioridazine, and raclopride) in the rat forebrain (Wan et al. 1995). The functional neuroanatomical profile of the newly introduced atypical agent ziprasidone has been studied and demonstrated that acute administration of ZIP induced a time-dependent increase in the density of c-Fos-positive nuclei in the shell and core of the nucleus accumbens, lateral and medial caudate putamen, and lateral septum (Jennings et al. 2006).

Previously, we have shown a substantial diversity in the stimulatory effect of the selected antipsychotics including haloperidol, clozapine, olanzapine, and risperidone on the quantity of c-Fos immunostained profiles in the PVN (Kiss et al. 2010). The aim of the present study was to test the effect of different doses of antipsychotics including aripiprazole (ARI), amisulpride (AMI), asenapine (ASE), haloperidol (HAL), clozapine (CLO), risperidone (RIS), quetiapine (QUE), olanzapine (OLA), ziprasidone (ZIP), and paliperidone (PAL) on the c-Fos expression in the PVN neurons.

\section{Materials and Methods}

Animals. Adult male Wistar rats weighing 280$300 \mathrm{~g}$ were used. They were housed in an animal facility with controlled temperature $\left(22 \pm 1^{\circ} \mathrm{C}\right)$, light (12-hour light/dark cycle with lights on at 06:00 h), 
and humidity (55\%). Animals were provided with dry pellets representing a regular rat chow and tap water ad libitum. Principles of the laboratory animal care and the experimental procedures used were approved by the State Veterinary and Food Administration of the Slovak Republic Committee and the investigation conditions were in accordance with the guidelines for the Care and Use of Laboratory Animals published by the U.S. National Institutes of Health.

Treatments. After acclimatization for several days in the animal facilities, the experimental animals received antipsychotics in the following doses: aripiprazole $1,10,30 \mathrm{mg} / \mathrm{kg}$ (ARI/1, ARI/10, ARI/30), amisulpride 10 and $30 \mathrm{mg} / \mathrm{kg}$ (AMI/10, AMI/30), asenapine $0.3 \mathrm{mg} / \mathrm{kg}$ (ASE), haloperidol 1 and $2 \mathrm{mg} / \mathrm{kg}$ (HAL/1, HAL/2), clozapine 10 and $20 \mathrm{mg} / \mathrm{kg}$ (CLO/10, CLO/20), risperidone 0.5 and $2 \mathrm{mg} / \mathrm{kg}$ (RIS/0.5, RIS/2), quetiapine 10 and $20 \mathrm{mg} / \mathrm{kg}$ (QUE/10, QUE/20), olanzapine 5 and $10 \mathrm{mg} / \mathrm{kg}$ (OLA/5, OLA/10), ziprasidone 10 and $30 \mathrm{mg} / \mathrm{kg}$ (ZIP/10, ZIP/30), and paliperidone $1 \mathrm{mg} / \mathrm{kg}$ (PAL)/body weight (b.w.). The individual antipsychotics were dissolved in $40 \mu \mathrm{l}$ of $20 \%$ acetic acid diluted to $1 \mathrm{ml}$ distilled water and adjusted to $\mathrm{pH} 6$ using $10 \mathrm{~N} \mathrm{NaOH}$. They were administered intraperitoneally. Controls received antipsychotic dissolvent. Ninety min after the treatments, the rats were anesthetized by a combined treatment of Zoletil (30 mg/kg, Virbac, Carros, France) and Xylariem $(15 \mathrm{mg} / \mathrm{kg}$, Riemser, Germany) in the volumes $0.1 \mathrm{ml}$ and $0.24 \mathrm{ml} / 300 \mathrm{~g}$ b.w., respectively and sacrificed by a transcardial perfusion with $60 \mathrm{ml}$ of saline containing $450 \mu \mathrm{l}$ of heparin (5000 IU/l, Zentiva, Slovakia) followed by $250 \mathrm{ml}$ of fixative containing $4 \%$ paraformaldehyde (Sigma-Aldrich, Germany) in $0.1 \mathrm{M}$ phosphate buffer ( $\mathrm{PB}, \mathrm{pH} 7.4)$. The brains were postfixed in a fresh fixative overnight, washed two times in $0.1 \mathrm{M} \mathrm{PB}$, infiltrated with $30 \%$ sucrose for 2 days at $4^{\circ} \mathrm{C}$, cut into $30 \mu \mathrm{m}$ thick coronal sections using Reichert-Jung, Cryo-cut $\mathrm{E}$ (Austria), and collected in a cryoprotectant solution at $-20^{\circ} \mathrm{C}$ until used. All the drugs used have been purchased in Sigma-Aldrich (Germany).

Brain areas investigated. The selection of coordinates for the hypothalamic PVN brain location was performed based on the rat brain atlas Paxinos and Watson (2007). The PVN-containing photomicrographs (4-6 sections/brain) were captured in AxioImager A1 light microscope (Carl Zeiss) coupled to a video camera and monitor. The photomicrographs with the presence c-Fos particles in the PVN were in more detail evaluated in the Adobe Photoshop 7.0.
Fos immunohistochemistry. Free-floating sections were repeatedly washed in cold $0.1 \mathrm{M}$ phosphate buffer $(\mathrm{PB})$ and preincubated in a blocking solution containing $0.3 \% \mathrm{H}_{2} \mathrm{O}_{2}$ in $0.1 \mathrm{M} \mathrm{PB}$ (Fisher Scientific, Fair Lawn, NJ, USA) for $20 \mathrm{~min}$ at room temperature (RT). Then the sections were rinsed $3 \times 10 \mathrm{~min}$ in $0.1 \mathrm{M} \mathrm{PB}$ and incubated with a polyclonal anti-c-Fos rabbit serum (12-7) diluted 1:1500 in $0.1 \mathrm{M}$ PB containing $4 \%$ normal goat serum (Gibco, Grand Island, NY, USA), 0.5\% Triton X-100 (Koch-Light Lab. Ltd., Colnbrook Berks, England), and $0.1 \%$ sodium azide (Sigma-Aldrich, Germany) for $48 \mathrm{~h}$ at $4^{\circ} \mathrm{C}$. After several rinsing in $\mathrm{PB}$, the sections were incubated with biotinylated goat antirabbit IgG (1:500, VectorStain Elite ABC Kit, Vector Lab., Burlingame, CA, USA) in PB for $90 \mathrm{~min}$ at RT. Next $\mathrm{PB}$ rinsing was followed by incubation with the avidin-biotin peroxidase complex (1:250) for $90 \mathrm{~min}$ at RT. After several washings in $0.05 \mathrm{M}$ sodium acetate buffer (SAB, pH6.0), Fos antigenic sites were visualized by nickel-enhanced 3,3'-diaminobenzidine tetrahydrochloride $(0.0625 \% \mathrm{DAB}, 2.5 \%$ nickel chloride, Sigma-Aldrich, No. 7718-54-9), in SAB containing $0.0006 \%$ hydrogen peroxide. The heavy metal-intensification of DAB yielded black staining in the c-Fos labeled nuclei. Developing of the color reaction was monitored under microscope, which lasted 6-10 min. After several washings in SAB, the tissue sections were mounted on positive charged adhesive slides, kept at RT for 120 min, coverslipped with Pertex (Stockholm, Sweden), and stored in histological boxes.

\section{Results}

Light microscopic inspection of the serial coronal sections covering the entire PVN extent carried out 90 min after an acute administration of various antipsychotics administered in different doses revealed distinct variabilities in the c-Fos expression response. From ten antipsychotics tested only six $\mathrm{ARI} / 10, \mathrm{CLO} / 10$ and $\mathrm{CLO} / 20, \mathrm{HAL} / 2.0, \mathrm{AMI} / 30$, OLA $/ 10$, and RIS $/ 2.0 \mathrm{mg} / \mathrm{kg}$ b.w. (Figures $1 \mathrm{C}, 1 \mathrm{E}, 1 \mathrm{~F}$, $1 \mathrm{H}, 1 \mathrm{~J}, 1 \mathrm{~L}, 1 \mathrm{~S})$ noticeable enhanced the number of Fos protein positive neurons in the PVN. Most apparent activation in c-Fos-labeled population of cells was observed after ARI $/ 10, \mathrm{CLO} / 20$, and OLA $/ 10 \mathrm{mg} / \mathrm{kg}$ b.w. (Figures 1C, 1F, 1L) treatments. Still strong c-Fos signal was observable in the PVN after administration of $\mathrm{CLO} / 10, \mathrm{HAL} / 2.0$, and RIS $/ 2.0 \mathrm{mg} / \mathrm{kg}$ b.w. (Figures 1E, 1H, 1S). Only a mild increase in the number of c-Fos immunoreactive cell bodies was noticed after treatment with ARI/1, ARI/30, HAL/1.0, 

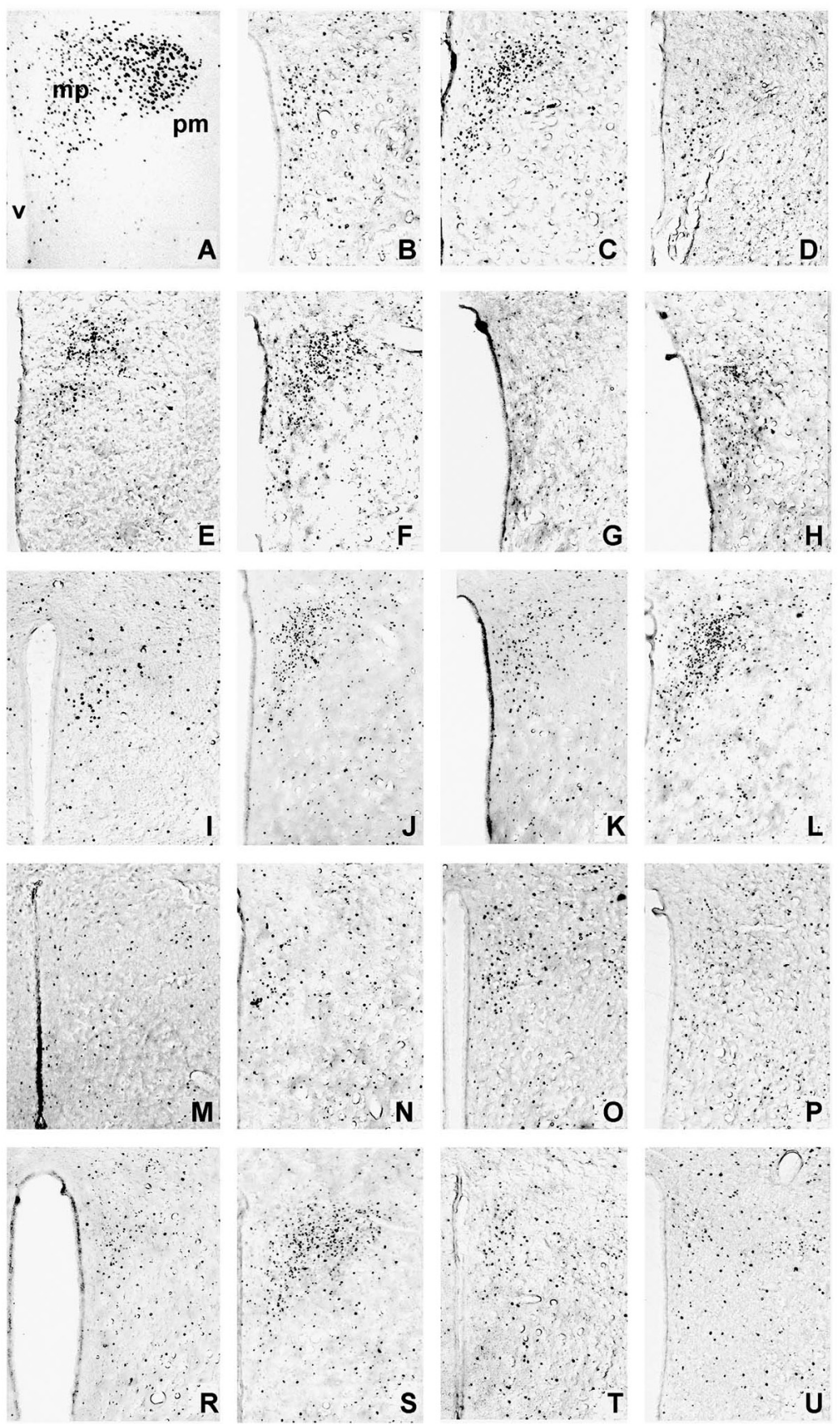

Figure 1. Photomicrographs demonstrating the acute effect of the individual antipsychotics on the c-Fos expression level in the PVN 90 min after the treatment. Most distinct c-Fos expression is seen in the cases of ARI/10 (C), CLO/10 (E) and 20/(F), HAL/2 (H), AMI/30 (J), OLA/10 (L), and RIS/2 (S) mg/kg b.w. treatments. The stimulatory effect of all of them is most marked in the PVN medial posterior subdivision, when compared with the illustrative photomicrograph A clearly depicting both the PVN medial posterior $(\mathrm{mp})$ and posterior magnocellular subdivisions $(\mathrm{mp})$. Lower responses in PVN c-Fos expression are recognizable in ARI/1 (B) and ARI/30 (D), AMI/10 (I), and OLA/5 (K). No evident marks in c-Fos expression stimulation is seen after ZIP/10 (M) and ZI/30 (N), QUE/10 (O), RIS/0.5 (S), PAL (T), and ASE (not shown) treatments, which are comparable with the effect of the vehicle (U) administration. 
AMI/10, OLA/5, and RIS/0.5 mg/kg b.w. (Figures 1B, $1 \mathrm{D}, 1 \mathrm{G}, 1 \mathrm{I}, 1 \mathrm{~K}, 1 \mathrm{R})$ in the PVN. Substantially lower c-Fos response, comparable to controls (VEH), was seen after ASE/0.3 (not shown), ZIP/10 and ZIP/30, RIS/0.5, PAL, and QUE/10 and QUE/20 mg/kg b.w. treatments (Figure 1). In contrast, neither of the RIS doses $(0.5$ or $1 \mathrm{mg} / \mathrm{kg})$ acutely administered to animals elevated the number of c-Fos protein positive neurons in the PVN (Figures 1R and 1S).

The topographic analysis revealed that the majority of c-Fos profiles after the treatments with potential antipsychotics occurred in the PVN medial parvocellular subdivision (mpPVN) at the middle level of the PVN. The distribution of c-Fos profiles is compared to an illustrative c-Fos immunostained PVN section (Figure 1A), which clearly depicts two large PVN subdivisions, i.e. the medial parvocellular (Figure $1 \mathrm{~A} \mathrm{mp}$ ) and the posterior magnocellular ones (Figure 1A pm) at the middle level of the PVN. The presence of c-Fos labeling after the treatment with the potential antipsychotics was less distinct in the PVN posterior magnocellular ( $\mathrm{pmPVN}$ ) subdivision as visible when compared to the c-Fos distribution on the illustrative PVN section (Figure 1A).

\section{Discussion}

In the present pilot study, a distinct c-Fos expression increase in the PVN was observed $90 \mathrm{~min}$ after the treatment with six ARI/10, CLO/10 and 20, $\mathrm{HAL} / 2, \mathrm{AMI} / 30, \mathrm{OLA} / 10$, and RIS $/ 2 \mathrm{mg} / \mathrm{kg}$ b.w. from ten (ARI, AMI, ASE, HAL, CLO, RIS, QUE, OLA, ZIP, PAL) antipsychotics tested. In all the potent antipsychotics, c-Fos-labeled profiles mainly occurred in the mpPVN subdivision and only scattered c-Fos-labeled profiles were detectable in the pmPVN subdivision at the middle level of the PVN.

The present pilot data may speak out for at least three outcomes. First, since only several antipsychotics induced c-Fos expression in the PVN, it is more than probable that the PVN structure will not belong to those extra-striatal structures, which might be considered as a common target area for all the antipsychotic drugs. Second, the antipsychotics used, except the ARI/30, produced a dose-dependent increase in the number of Fos protein positive neurons in the PVN. Third, c-Fos response in the PVN indicates that the effect of the potential antipsychotics is predominantly directed to a subset of neurons located in the mpPVN subdivisions. The last finding is in agreement with our previous study (Kiss et al. 2010), in which antipsychotics OLA/30, $\mathrm{CLO} / 30, \mathrm{RIS} / 2, \mathrm{HAL} / 1$ after $60 \mathrm{~min}$ of the treatment induced c-Fos expression mainly in the mpPVN at the comparable extent as demonstrated in the present pilot study.

In the mpPVN, a wide variety of neuropeptidessynthesizing neurons have been identified (Kiss 1988). Therefore, it has to be taken into the consideration that c-Fos expression increase in the pmPVN subdivision after the potential antipsychotics treatments may notionally target any of the neuronal phenotypes localized in this PVN subdivision including CRH (Swanson et al. 1983; Sawchenko et al. 1984; Lennard et al. 1993), neurotensin (NT) (Ceccatelli et al. 1989), enkephalin (ENK) (Merchenthaler 1992; Beaulieu et al. 1996), somatostatin (Ishikawa et al. 1987; Merchenthaler et al. 1989), vasoactive intestinal polypeptide (VIP) (Toni et al. 1990; Dalcik and Phelps 1993), cholecystokinin (CCK) (Ceccatelli et al. 1989), TRH (Segerson et al. 1987; Merchenthaler and Liposits 1994), galanin (GAL) (Palkovits et al. 1987), AVP (Hou-Yu et al. 1986), and OXY (HouYu et al. 1986). In addition, the coexistence of two or more of these peptides in the mpPVN neurons is a common event, however, their functional significance, except the CRH-AVP co-expression, is not fully understood. Multitude simultaneous occurrence of neuromediators in PVN cellular units might lead to a more divergent functional specification with a possible role in the functional plasticity of fixed anatomical circuit (Kiss 1988). Actually, Ceccatelli et al. (1989) have shown that about $30 \%$ of the CRF neurons contain NT and 20\% ENK, whereas about $60 \%$ of both NT- and ENK-immunoreactive neurons lacked CRF-LI.

From the above-mentioned literature data, it comes out that the CRH neurons form the most extensive and densest cell aggregation (80\% from 2000 CRH cells) in the mpPVN subdivision. Park and co-workers (2011b) have shown that haloperidol may stimulate CRF mRNA expression in the PVN under basal conditions, while ZIP administration does not, although in the same experiment, chronic ZIP treatment prevented CRF mRNA expression increase induced by immobilization stress. This clearly head towards the fact that different antipsychotics may play a different role in the regulation of the CRH perikarya in the mpPVN. Actually, in the present study, in agreement with the above-mentioned one, no marked c-Fos induction in the PVN was observed neither after lower nor higher doses of ZIP acute treatment under basal conditions. In vitro studies have shown that QUE and OLA are able to acutely reduce the release of $\mathrm{CRH}$ from isolated rat hypothalami and hippocampi (Tringali et al. 2009) 
and HAL, CLO, and RIS may inhibit the CRH-CAT activity, indicating that some of the antipsychotic drugs by the inhibition of CRH gene promoter activity may negatively affect, i.e. inhibit the activity of the HPA axis (Basta-Kaim et al. 2006). Previously, we have also described the effect of several atypical neuroleptics on the activity of pmPVN magnocellular neurons. Namely, CLO and OLA acute treatments revealed c-Fos colocalizations with both AVP- and OXY-displaying magnocellular perikarya in the pmPVN. This finding clearly indicates that not only parvocellular but also magnocellular perikarya may be a target for some of the antipsychotics (Kiss et al. 2010). However, there is only a limited number of studies in the literature available dealing with the effect of antipsychotics on c-Fos expression in the PVN directed to the analysis of the phenotype character of the activated cells.

In spite of the fact that many antipsychotics act via a number of different receptors, it is still not clear whether the effect of the potential antipsychotics on the population of neurons located in the mpPVN subdivision is direct or indirect. There is also a limited number of studies demonstrating how importantly the individual antipsychotics might be involved in the regulation of the PVN neurons activity and consequently in the regulation of different functional circuits originating or mediating by these
PVN neurons. Actually, He and co-workers (2013) have shown that antagonizing of the hypothalamic $\mathrm{H}_{1}$ receptors by CLO or OLA may time-dependently affect the hypothalamus-brainstem circuits leading to a weight gain.

In summary, the attempt of the present pilot study was to depict an outline of the possible extra-striatal action of different doses of ten antipsychotics selected in the PVN. The c-Fos expression in the mpPVN induced by the potential antipsychotics may speak out for a possibility to affect a wide range of neuronal phenotypes involved in different intrinsic and extrinsic brain circuits.

\section{Acknowledgement}

The author is grateful for the c-Fos antibody (No. 2-17) as a generous gift of Dr. Jens D. Mikkelsen (Denmark), the excellent technical assistance of Dr. R. Koprdova (Institute of Experimental Pharmacology and Toxicology, Slovak Academy of Sciences, Slovakia), Dr. J. Osacka, Dr. L. Horvathova, and A. Cernackova (Institute of Experimental Endocrinology, Biomedical Research Center, Slovak Academy of Sciences, Slovakia) and the financial support of 2/0031/16 VEGA grant of the Slovak Academy of Sciences and APVV-15-0037 grant of the Research and Development Agency of the Slovak Republic.

\section{References}

Alexander K, Nikodemova M, Kucerova J, Strbak V. Colchicine treatment differently affects releasable thyrotropinreleasing hormone $(\mathrm{TRH})$ pools in the hypothalamic paraventricular nucleus (PVN) and the median eminence (ME). Cell Mol Neurobiol 25, 681-695, 2005.

Basta-Kaim A, Budziszewska B, Jaworska-Feil L, Tetich M, Kubera M, Leskiewicz M, Otczyk M, Lason W. Antipsychotic drugs inhibit the human corticotropin-releasing-hormone gene promoter activity in neuro-2A cellsan involvement of protein kinases. Neuropsychopharmacology 31, 853-865, 2006.

Beaulieu J, Drolet G, Chanpagne D. Enkephalin innervation of the paraventricular nucleus of the hypothalamus: Distribution of fibers and origins of input. J Chem Neuroanat 10, 79-92, 1996.

Blake NG, Johnson MR, Eckland DJA, Foster OJF, Lightman SL. Effect of food deprivation and altered thyroid status on the hypothalamic-pituitary-thyroid axis in the rat. J Endocrinol 133, 183-188, 1992.

Ceccatelli S, Eriksson M, Hokfelt T. Distribution and coexistence of corticotropin-releasing factor-, neurotensin-, enkephalin-, cholecystokinin-, galanin- and vasoactive intestinal polypeptide/peptide histidine isoleucine-like peptides in the parvocellular part of the paraventricular nucleus. Neuroendocrinology 49, 309-323, 1989.

Ceccatelli S, Cortes R, Hokfelt T. Effect of reserpine and colchicine on neuropeptide mRNA levels in the rat hypothalamic paraventricular nucleus. Brain Res Mol Brain Res 9, 57-69, 1991.

Dalcik H, Phelps CJ. Median eminence-afferent vasoactive intestinal peptide (VIP) neurons in the hypothalamus: localization by simultaneous tract tracing and immunocytochemistry. Peptides 14, 1059-1066, 1993.

Fujimura M, Hashimoto K, Yamagami K. The effect of the antipsychotic drug mosapramine on the expression of Fos protein in the rat brain: comparison with haloperidol, clozapine and risperidone. Life Sci 67, 2865-2872, 2000.

Hallbeck M. Dynorphin mRNA-expressing neurons in the rat paraventricular hypothalamic nucleus project to the spinal cord. Neurosci Lett 285, 161-1642000.

Hallbeck M, Larhammar D, Blomqvist A. Neuropeptide expression in rat paraventricular hypothalamic neurons that 
project to the spinal cord. J Comp Neurol 433, 222-238, 2001.

He M, Deng C, Huang X. The role of hypothalamic H1 receptor antagonism in antipsychotic-induced weight gain. CNS Drugs 27, 423-434, 2013.

Herman JP, Figueiredo H, Mueller NK, Ulrich-Lai Y, Ostrander MM, Choi DC, Cullinan WE. Central mechanisms of stress integration: hierarchical circuitry controlling hypothalamo-pituitary-adrenocortical responsiveness. Front Neuroendocrinol 24, 151-180, 2003.

Herman JP, Flak J, Jankord R. Chronic stress plasticity in the hypothalamic paraventricular nucleus. Prog Brain Res 170, 353-364 2008.

Hill JW. PVN pathways controlling energy homeostasis. Indian J Endocrinol Metab 16, S627-S636, 2012.

Hou-Yu A, Lamme AT, Zimmerman EA, Silverman AJ. Comparative distribution of vasopressin and oxytocin neurons in the rat brain using a double-label procedure. Neuroendocrinology 44, 235-246, 1986.

Ishikawa K, Taniguchi Y, Kurosumi K, Suzuki M, Shinoda M. Immunohistochemical identification of somatostatincontaining neurons projecting to the median eminence of the rat. Endocrinology 121, 94-97, 1987.

Jennings CA, Cluderay JE, Gartlon J, Cilia J, Lloyd A, Jones DN, Southam E. The effects of ziprasidone on regional c-Fos expression in the rat forebrain. Psychopharmacology (Berl) 184, 13-20, 2006.

Kiss JZ. Dynamism of chemoarchitecture in the hypothalamic paraventricular nucleus. Brain Res Bull 20, 699-708, 1988.

Kiss A, Pirnik Z, Bundzikova J, Mikkelsen JD. Different antipsychotics elicit different effects on magnocellular oxytocinergic and vasopressinergic neurons as revealed by Fos immunohistochemistry. J Neurosci Res 88, 677$685,2010$.

Lennard DE, Eckert WA, Merchenthaler I. Corticotropin-releasing hormone neurons in the paraventricular nucleus project to the external zone of the median eminence: a study combining retrograde labeling with immunocytochemistry. J Neuroendocrinol 5, 175-181, 1993.

Merchenthaler I, Setalo G, Csontos Cs, Petrusz P, Flerko B, Vilar AN. Hormone- and somatostatin-containing neurons projecting to the median eminence of the rat. Endocrinology 125, 2812-2821, 1989.

Merchenthaler I. Enkephalin-immunoreactive neurons in the parvicellular subdivisions of the paraventricular nucleus project to the external zone of the median eminence. JCN 326, 112-120, 1992.

Merchenthaler I, Liposits Z. Mapping of thyrotropin-releasing hormone (TRH) neuronal systems of rat forebrain projecting to the median eminence and the OVLT. Immunocytochemistry combined with retrograde labeling at the light and electron microscopic levels. Acta Biol Hung 45, 361-174, 1994.

Palkovits M, Rokaeus A, Antony FA, Kiss A. Galanin in the hypothalamo-hypophyseal system. Neuroendocrinology $46,417-423,1987$.

Park JI, Zhao T, Huang GB, Sui ZY, Li CR, Han EH, Chung YC. Effects of aripiprazole and haloperidol on Fos-like immunoreactivity in the prefrontal cortex and amygdala. Clin Psychopharmacol Neurosci 9, 36-43, 2011a.

Park SW, Choi SM, Lee JG, Lee CH, Lee SJ, Kim NR, Kim YH. Differential effects of ziprasidone and haloperidol on immobilization-stress-induced CRF mRNA expression in the hypothalamic paraventricular nucleus of rats. Neuropsychobiology 63, 29-34, 2011b.

Paxinos G, Watson C. The Rat Brain in Stereotaxic coordinates, compact 6th ed. Academic Press, Sydney, 2007.

Pezarro Schimmel LN, Banasikowski TJ, Hawken ER, Dumont EC, Beninger RJ. Brain regions associated with inverse incentive learning: $c$-Fos immunohistochemistry after haloperidol sensitization on the bar test in rats. Behav Brain Res 293, 81-88, 2015.

Rajkumar R, See LK, Dawe GS. Acute antipsychotic treatments induce distinct c-Fos expression patterns in appetiterelated neuronal structures of the rat brain. Brain Res 1508, 34-43, 2013.

Ranson RN, Motawei K, Pyner S, Coote JH. The paraventricular nucleus of the hypothalamus sends efferents to the spinal cord of the rat that closely appose sympathetic preganglionic neurones projecting to the stellate ganglion. Exp Brain Res 120, 164-172, 1998.

Sawchenko PE, Swanson LW, Vale WW. Corticotropin-releasing factor: co-expression within distinct subsets of oxytocin-, vasopressin-, and neurotensin-immunoreactive neurons in the hypothalamus of the male rat. J Neurosci 4, 1118-1129, 1984.

Sawchenko PE, Swanson LW. Localization, colocalization, and plasticity of corticotropin-releasing factor immunoreactivity in rat brain. Fed Proc 44, 221-227, 1985.

Segerson TP, Hoefler H, Childers H, Wolfe HJ, Wu P, Jackson IM, Lechan RM. Localization of thyrotropin-releasing hormone prohormone messenger ribonucleic acid in rat brain in situ hybridization. Endocrinology 121, 98-107, 1987.

Semba J, Sakai M, Miyoshi R, Mataga N, Fukamauchi F, Kito S. Differential expression of c-fos mRNA in rat prefron- 
tal cortex, striatum, N. accumbens and lateral septum after typical and atypical antipsychotics: an in situ hybridization study. Neurochem Int 29, 435-442, 1996.

Silverman AJ, Hou-Yu A, Chen WP. Corticotropin-releasing factor synapses within the paraventricular nucleus of the hypothalamus. Neuroendocrinology 49, 291-299, 1989.

Swanson LW, Kuypers HGJM. The paraventricular nucleus of the hypothalamus: Cytoarchitectonic subdivisions and organization of projections to the pituitary, dorsal vagal complex, and spinal cord as demonstrated by retrograde fluorescence double-labeling methods. J Comp Neurol 194, 555-570, 1980.

Swanson LW, Sawchenko PE. Paraventricular nucleus: a site for the integration of neuroendocrine and autonomic mechanisms. Neuroendocrinology 31, 410-417, 1980.

Swanson LW, Sawchenko PE. Hypothalamic integration: organization of the paraventricular and supraoptic nuclei. Annu Rev Neurosci 6, 269-324, 1983.

Swanson LW, Sawchenko PE, Rivier J, Vale WW. Organization of ovine corticotropin-releasing

factor immunoreactive cells and fibers in the rat brain: an immunohistochemical study. Neuroendocrinology 36 , $165-186,1983$.

Swanson LW, Sawchenko PE, Lind RW. Regulation of multiple peptides in CRF parvocellular neurosecretory neurons: implications for the stress response. Prog Brain Res 68,169-190, 1986.

Toni R, Jackson IM, Lechan RM. Neuropeptide-Y-immunoreactive innervation of thyrotropin-releasing hormonesynthesizing neurons in the rat hypothalamic paraventricular nucleus. Endocrinology 126, 2444-2453, 1990.

Tringali G, Lisi L, De Simone ML, Aubry JM, Preziosi P, Pozzoli G, Navarra P. Effects of olanzapine and quetiapine on corticotropin-releasing hormone release in the rat brain. Prog Neuropsychopharmacol Biol Psychiatry 33, 1017-1021, 2009.

Wan W, Ennulat DJ, Cohen BM. Acute administration of typical and atypical antipsychotic drugs induces distinctive patterns of Fos expression in the rat forebrain. Brain Res 688, 95-104, 1995.

Zhao C, Li M. Neuroanatomical substrates of the disruptive effect of olanzapine on rat maternal behavior as revealed by c-Fos immunoreactivity. Pharmacol Biochem Behav 103, 174-180, 2012. 